\title{
Editorial
}

\section{Anterior segment malformations: aetiology and genetic implications}

New theories in science and medicine seem to gain wider recognition if they are seen to be controversial and to threaten to demolish their predecessors. Often, however, the novelty appears in retrospect to be less substantial and due more to semantic change.

In 1966, Reese and Ellsworth published a paper entitled "The anterior chamber cleavage syndrome" in which they attempted to group together several anomalous conditions of development of the front of the eye. In so doing they were aware that the concept which they termed 'faulty cleavage' as applied to Axenfeld's anomaly, Peters' anomaly and Reiger's anomaly might be misunderstood. They anticipated later criticism by affording it a wide definition so as to include 'all possible factors such as improper differentiation, absorption and even shifting or mobilisation of tissue in its developmental stage'. Despite this breadth of meaning given to the term, the word 'cleavage' itself failed to convey all that the authors intended, and a misconcept of it was remembered.

This made it easier for the next major synthetic theory, proposed by Kupfer and Kaiser-Kupfer, to gain attention. ${ }^{2}$ In this the novelty was not so much to counter the idea that cleavage occurred to produce the angle structures of the anterior chamber as that the tissues which develop therein are formed from cells of neural crest origin. It was already known that three waves of mesodermal cells, later called mesenchyme, invaded the surface ectoderm during the formation of the cornea, but these authors cited marker studies in evidence for an origin in the neural crest. In this way abnormality of neural crest cells could be a cause of the various developmental defects described.

There are two strong reasons for emphasising this. The first was that it allows the idea of a cell type, with a possible genetic defect, failing to develop and differentiate normally in its destination site, such as the iris stroma or the trabecular meshwork. The second was that it provided an explanation of the coincidence of other abnormalities such as dental and facial defects seen in many cases of anterior eye anomaly.

Many subsequent reports have linked genetic and chromo- somal defects with anterior segment malformations of the eye. In the paper presented in this issue by Holmström and colleagues evidence is given for the possibility in some cases of a gene defect with an autosomal dominant inheritance. The variation in abnormality in affected family members is presumably due to variable expression of the gene. They point to a particular problem which derives from this variability, which is that some of the offspring of mildly affected mothers were severely affected. This was not to be expected because of the absence of extraocular defects, and so, without the knowledge that a dominant gene was responsible accurate predictions of risks to offspring could not be made.

Work on the human genome, as on the Channel Tunnel, continues relentlessly and will eventually produce dramatic results. The pace of progress in genetics is particularly impressive. In the past decade the number of loci which have been mapped to specific chromosomes has risen from a few dozen to approximately 2000 . In the same period the number of gene probes which may be used in linkage studies has reached over $5000 .^{3}$ It is likely that we shall not have to wait long for a gene probe for Reiger's syndrome. This will then provide the opportunity for prenatal identification of affected individuals and improved genetic advice. In the meantime, and in any case, the clinician dealing with an infant with anterior ocular malformation must remember to inquire fully into the family history and examine the eyes of the parents and siblings. He should then refer to a paediatrician to exclude other defects such as dental, heart, and limb deformity and deafness, as well as seeking the advice of a clinical geneticist, as an integral part of the management of the eye disorder and its complications.

\section{R M L DORAN}

1 Reese A, Ellsworth R. The anterior chamber cleavage syndrome. Arch Ophthalmol 1966; 75: 307-18.

2 Kupfer C, Kaiser-Kupfer M. New hypothesis of developmental anomalies of the anterior chamber associated with glaucoma. Trans Ophthalmol Soc UK 1978; 98: $213-5$

3 McKusick V. (Appendix to Foreword). Mendelian inheritance in man. 9th ed. Baltimore: Johns Hopkins University, 1990. 